\title{
A Personal Interview with M. Stuart Hunter
}

\section{David F. Rielley}

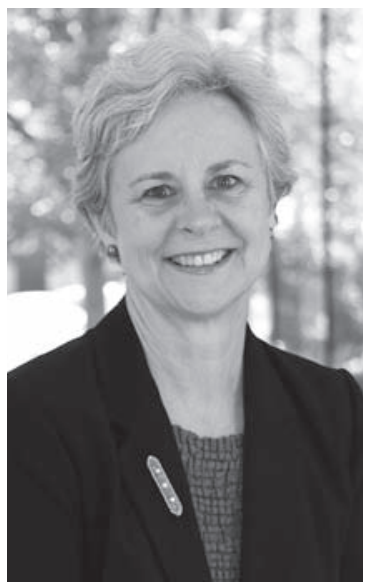

Since the early 1980 's, the National Resource Center for the First Year Experience and Students in Transition (NRC) at the University of South Carolina has been the leader in improving the experience of first-year and transfer students, most notably via the first-year experience (FYE) seminar. Currently Executive Director of the NRC, Mary Stuart Hunter, has been associated with the FYE movement from the beginning (Note: the NRC celebrated its 30th annual conference in February, 2011). Recently, she spoke with David Rielley (a senior associate editor of The Journal of College Orientation and Transition) about how the first-year experience has changed over the years, current trends, and advice for professionals in the field of college orientation and transition.

Rielley: Stuart, you've been at South Carolina since the NRC was founded. How have you seen this field of first-year programs and orientation change?

Hunter: A couple of ideas spring to mind when you ask that question. I think the first-year experience in its broadest sense, which includes orientation and all the other aspects involved in the students' first year, has become an academic sub-specialty. There is now a literature base, research going on in these areas, and institutions are now devoting both financial and human resources to these areas. I think FYE initiatives are less marginalized than they once were in the academy because the research and assessment-based evidence [shows] that these efforts make significant differences in the lives of students and in their success. So we're talking about 30 years of effort and many people working very hard; that's a long time, but the FYE has become an academic discipline itself. Another piece of evidence is [that] Kennesaw State University in Georgia is in the process of creating a master's degree in what I think they're calling the first-year experience. So, it truly has become a sub-specialty in higher education, and I would have never guessed that 30 years ago when we were struggling to create a journal that would encourage research in this area. The fact that NODA considers the first-year experience an

David F. Rielley (rielleyd@missouri.edu) is the Director of New Student Programs, Senior Coordinator in the Department of Student Life at the University of Missouri-Columbia, and a Senior Associate Editor of The Journal of College Orientation and Transition. 
extension of their original work, the fact that NASPA has a significant number of sessions at their annual national conference, the fact that ACPA has a commission that includes orientation, transition, and first-year experience-these are all indications that this is a significant area of academic inquiry.

Rielley: In terms of programming, what have you seen change?

Hunter: When you look broadly at the orientation transition, one thing that we've seen change significantly over the past couple of decades is the fact that orientation on many campuses has evolved from primarily addressing the social adjustment of the students to now including academic orientation to the university as well. Orientation goes beyond just the scheduling of classes and student development kinds of activities that occurred years ago. We now have the emergence of first-year reading experiences where institutions organize a common academic experience with students during the earliest days on campus. Many campuses are holding academic convocations as ceremonial welcomes to the campus in addition to the traditional social activities and events that are planned during those welcome weeks. I've see orientation become more mainstream in [colleges and] universities and engage a wider group of faculty, administrators, programs and activities on campus.

Rielley: Looking specifically at FYE-type classes, has the content or focus of those classes changed much over the years?

Hunter: I think so. Early on these courses were more heavily weighted toward the orientation type of seminar course. Now we know that there are a variety of types of first-year seminars. What we see when you look at trends [is that] a larger percentage tends toward a more academic seminar where many of the transition issues might be covered in the content but the course also has academic focus to it. In some instances, a campus has individual academic seminars where students select a section of the course based on a topic; in others, the campus chooses a theme for the year, and all sections are theme-based but are taught by faculty and staff from all over the campus, both from student affairs and academic affairs. So we've seen a shift away from the traditional type of seminar being an orientation-to-college type class to include more substantial content directly related to the academic experience.

Rielley: Let's shift from programming to focus on students. This fall the University of Missouri Columbia used Generation Me, Jean Twenge's summary of her meta-analysis on changing generational attitudes and behaviors, in our summer reading program. She has some pretty strong opinions. How have you seen students change over the past $10-20$ years?

Hunter: Of course, my response to that is based on my experience here at the University of South Carolina. We've definitely seen changes in the attitudes, 
behaviors, and experiences that our students bring with them as evidenced by the UCLA Higher Education Research Institute's CIRP (Cooperative Institutional Research Program) survey. We have shifts and changes in the trends, and changes in the students. My experience in the classroom is that students are coming much more academically capable and [are] better able to do college-level work. They are also much more distracted. Growing up in the information age has been more challenging for students today than it was for earlier generations because there is so much at their fingertips. It's hard for them to know where to go. I see them coming to us far worldlier, with far more experiences with the world and cultural diversity. Many of them have had more opportunities than other students had years ago. It's a reflection of our society, of course, but also a reflection of their educational experiences. So, they're coming in with much more experience under their belts, but they're also coming into a much more challenging world and a world that expects far more of them.

Rielley: Do you think that access to all the technology and information that is available to students is going to cause a shift in what we teach? That rather than teaching information directly, the emphasis will be more on how to access information?

Hunter: I'm not the expert on this, but what we are seeing, from the academic perspective and from the perspective of faculty and staff on campuses, is that this information boom has caused us to think more deeply and return more to the basics of general education. Rather than trying to teach it all, we're helping students better understand how to think, how to analyze things, and how to communicate. Today's society is helping to focus us back on the earlier purposes of general education-analytical thinking, effective communication, dealing with unstructured problems, being an active learner, knowing how to find information. It's almost forcing us to rethink how students learn and what we think is important for them to learn. You hear the statistic that the some of the career fields that will be available to students after they graduate technically don't exist yet. You see that a lot in technical areas, and that the things first-year students learn this year will be obsolete by the time they graduate. It really does sort of force us to begin to think more about how we learn, how we gather information, how we make sense of that information as opposed to simply learning the facts.

Rielley: Do you care to make any predictions of where this change is going to take us in the world of orientation and first-year programs?

Hunter: What we need to emphasize with students are their own information-seeking skills, problem solving skills and research abilities. We need to help them understand that everyone needs help in some ways now and then, and that the truly smart and strong person is the one who seeks out help when they need it. Our society places such an emphasis on individual strength, especially for our young men, that they are reluctant to seek help because they 
think that makes people think they are weak, and that's not a good thing. It's not just with the men; it's with all students, but especially with the guys. One of the things we really need to do as orientation and first-year educators is to help students learn how to solve their own problems, how to find their own information, how to make their own way in the world, and how to be intentional about what they do and where they're headed-they can't sit back and let someone give it all to them because that's probably not going to happen. They need to be intentional about their decisions, assertive and intentional about their direction, and go after it.

Rielley: How have your personal interests in the field changed over the years?

Hunter: One thing that has most interested me recently is the area of emotional intelligence. I don't know how much of that is a part of my experience and my work; I can't separate that from my experience as a parent, but I've had a real sort of awakening recently about what separates students who are successful from ones that are not successful. Students' academic and cognitive abilities do factor in because they have got to have some level of intelligence to be able to soar. But when I see students who don't succeed at our university, usually their lack of success doesn't have to do with how smart they are or are not. Usually it's with how they can manage themselves, how they can structure their time, how they can make decisions intentionally, how they can deal with impulse control, how resilient they are, how they can deal with their ability to reframe their thinking, how they can deal with stress management, how they can be flexible, how they can interact with each other. So I've been very interested in the last few years in the whole area of emotional intelligence.

Rielley: As you look at that area, are you familiar with the StrengthsQuest program?

Hunter: I am, and I very much like what they've done. I've dabbled with that a little bit in my own first-year seminar class. Also, appreciative advising is another area that holds tremendous potential. Laurie Schreiner has been doing some good work with the strengths movement, and Jennifer Bloom has advanced the work with appreciative advising. These areas both have to do in part with those non-cognitive abilities and the fact that these approaches are supportable, and teachable, and developmental. So there's a lot of exciting work going on out there.

Rielley: A focus of these interviews is to talk about professional preparation. From your experience, what do you think are some of the skills and competencies that new professionals in this field need to possess?

Hunter: A lot of the same things I was talking about [in terms of] emotional intelligence competencies. The ability to see the big picture, to plan ahead, and to be intentional about what new professionals do [is important]. The ability to 
put together a set of experiences during their graduate preparation programs that will make them marketable in seeking their first job is important. If students can get involved in a variety of different offices and programs as opposed to focusing on just one functional area, if they can do the kinds of things that professionals do in that they challenge themselves academically, if they can somehow get published while in graduate school, if they can find ways to make presentations at professional conferences, all of those sorts of things will help them get that first job.

One of the things that is most important for students as they are looking for their first jobs is not what the job is, but for whom they will work, who will supervise them, and how much they are willing to mentor, support, and provide opportunities. That first job is probably going to last only two or three years before they move on to the next opportunity. What is important in that first position is a setting where new professionals can thrive, where they can grow, where they can develop. So to me, the most important thing is who is going to be supervising and directing your work.

Mentoring young people is so important. I had a tremendous mentor in John Gardner, but I also had another mentor who took me under her wing, a woman who was about 15 years older than me. We would go to lunch about once a week - this was early in my career-and she would pose complex professional and ethical questions to me, "What do you think about this or that?" Just having that relationship with her really helped me crystallize my work values and some of the things that I was doing professionally. I think it's important for younger folks to seek someone out, whether it's your supervisor or someone else on campus, and to develop that relationship. And for people who are more senior in their career, I think it's really important to [mentor] the younger professionals.

Rielley: Along the lines of professional preparation, what do you consider as required readings in the field of orientation and first-year experience? If you're putting together a class, what would you have them read?

Hunter: Well, clearly the "Bible" of the FYE field right now is the Upcraft, Gardner, and Barefoot book, Challenging and Supporting the First-Year Student (2005). That's sort of a dry academic book, but I think it provides a true and broad perspective. I would also have them read whatever the students are reading, whatever is on the best-seller list at the time. And that would change from month to month, year to year. But I would definitely have them getting into the minds of students the best they can.

Rielley: Does this mean I've got to start reading the Twilight series?

Hunter: Well, I think you can probably skim, or even skip, that. But read what the students are reading, participate in the social media because that's where they're 
spending most of their time reading. Even if you just experience it yourself, I think it helps. Keeps you young, keeps you thinking as they do, and experiencing some kinds of things that they experience.

Rielley: As you look over your time in the field, have there been any watershed events, publications, or other types of changes that you think have taken the field in a different or new direction?

Hunter: The work that's coming out of the AAC\&U [American Association of Colleges \& Universities] and the NSSE [National Survey of Student Engagement] at Indiana University have really helped to shape how higher education thinks about itself today and how we organize our institution. Most recently, the work in the DEEP [Documenting Effective Educational Practices] project and the LEAP [Liberal Education and America's Promise] work out of AAC\&U is very important. Clearly, all of the assessment work is extremely important. I would want them to read the article from 1995 that was in Change magazine by Bob Barr and John Tagg about the paradigm shift between instructional institutions and learning institutions. I still go back to that time and time again simply because it helps me frame how I am teaching as well as how I conduct faculty development and professional development activities. So, I would recommend that article to everyone. I still think that Nevitt Sanford and Art Chickering's work are pretty important to those of us in the field. We have to continue to understand and think about student development theory as we plan our programs and do our work. So, I think some of those classics are still important. Finally, the work of Patrick Terenzini and Ernest Pascarella, How College Affects Students (2005), helps us synthesize the vast body of research that informs our field.

Rielley: What's been your fondest memory or interaction that's had the most impact on your career?

Hunter: Wow, that's a good question. I've been so blessed to be able to meet people from all over the world because of the work in the National Resource Center for The First-Year Experience and Students in Transition and our international conference work. It's not a single event or memory, but the fact that I've been able to work with people from other cultures related to the first-year experience. I've done a good bit of work in Japan and last spring, I went to Hong Kong to help educators there think through the creation of the first year from scratch. In Hong Kong, the higher education system is in the process of changing from a three-year undergraduate degree to a Chinese system that is more analogous to our four-year degree. In the fall of 2012, Hong Kong will bring in a double cohort of first-year students, and their institutions are in the process of architecting and creating a firstyear experience. The ten days I spent in Hong Kong last spring were probably one of the highlights of my career because I was there as a consultant to eight different institutions and helped them think through what a first-year experience could look like. 
Rielley: Starting something completely from scratch...

Hunter: It's awesome, and some of the institutions still looked like deer in the headlights; others had developed these elaborate models and ways of thinking. What's most interesting about working with other cultures and people from other countries is that it forces us to really communicate what we do at the most basic level because the educational cultures are so different. You can't make assumptions that what they're doing is similar to what we're doing. You go back to "why." Why do we do what we do, and what do we base it on? It really forces you to think more intensely and deeply about what we do and why we do it. As you well know, we go to conferences here and everybody's thinking from the same language. Even if you're at very different types of institutions, the way you communicate is the same. Everyone knows what NSSE is, what student engagement is, and why it's important. So, when you go to a different culture, you have to explain that, and you have to take it down to its most basic elements. Making complex things simple and understandable to people is back to teaching again. You go back to having to think very basically about something. To me, it's very exciting to have to do that.

Rielley: Knowing what you know now, what do you wish you had known as a new professional?

Hunter: It would always be nice to have a crystal ball, to know what your career path is going to be so that you can really focus on developing an area of expertise and a body of knowledge that will support you throughout your entire career. When I think of all the things I've read and experienced, if I'd done a better job of organizing my insights and "aha" moments and capturing them in a way that I could draw on them later-I really wish I'd been able to do that. It's back to the whole concept of integrative learning. One of the things we want students to be able to do now is integrate what they are learning in one setting with what they are experiencing in another, then be able to draw on those experiences later and make what they are doing more meaningful and deeper. So, what I wish I had done was create some kind of system for organizing everything that I was experiencing in a way that I could remember it and make sense of it and draw on it. Maybe if I'd kept a journal, or done a better job of reflecting on my experiences at the time, it would have made a difference. Find a way to journal your experiences and "connect the dots" as you develop. Intention and reflection are two concepts that will deepen a career path. I wish I had realized this 30 years ago! 
American College Personnel Association. www.myacpa.org Association of American Colleges \& Universities. www.aacu.org

Barr, R. B., \& Tagg, J. (1995, November/December). From teaching to learning-a new paradigm for undergraduate education. Change, 27(6): 12-25.

Higher Education Research Institute. www.heri.ucla.edu

National Association of Student Personnel Administrators. http://www.naspa.org/

National Resource Center for the First Year Experience and Students in Transition. http://sc.edu/fye

Pascarella, E. T., \& Terenzini, P. T. (2005). How college affects students: A third decade of research (Vol. 2). San Francisco: Jossey-Bass.

Upcraft, M. L., Gardner, J. N., \& Barefoot, B. O. (Eds.). (2005). Challenging and supporting the first-year student: A handbook for improving the first year of college. San Francisco: Jossey-Bass. 